\title{
Performance Evaluation for Production of 5000kgHydraulic Jack
}

\author{
AminuSaleh Mohammed, Dr. Ibrahim OnuweAbdulmalik \\ Hydraulic Equipment Development InstituteKumbotso .P.M.B 3067, KanoNigeria
}

\begin{abstract}
The report submitted presents detailed performance evaluation analysis for production of 5tonne hydraulic jack. The main task is to produce it using two approaches namely conversional and reverse engineering. Conversional design team were able to design the jack with all the necessary tolerance and limits, those involve design calculations, producing standard drawing and cost analysis on each part involve. While reverse engineering team were able to produce the jack through reverse engineering procedures and approach, this involve selection of materials needed to produce the parts with our machines in the workshop, test analysis for each component, assembling and testing to ensure effective performance.

Keyword: Control pressure, fluid reservoir, Hydraulic cylinder.
\end{abstract}

\section{Significance}

The significance of this work is to produce a $5000 \mathrm{~kg}$ hydraulic jack with locally available materials which would go a long way for the increase in output of locally fabricated equipment, decrease in price of these equipment and jobs creation for our numerous unemployed graduates, which at the end will generally improve the economy of the country.

\section{Introduction}

The study of hydraulic deals with the use and characteristics of the liquid, earlier recorded history shows that devices such as pumps and water wheels were known in very ancient times. It was not, however until $17^{\text {th }}$ century that the branch of hydraulics with which we are to be concerned first came in use.

Hydraulics now could be defined as a means of transmitting power by pushing on a confined liquid, the input component of the system is called pump while the output is called an actuator.

\subsection{HYDRAULIC PUMPS}

The pump is probably the most important and least understood component in the hydraulic system. Its function is to convert mechanical energy by pushing the hydraulic fluid into the system. Pumps are made in many different pumping mechanisms and for many different purposes. With all the technological developments that have accrued since ancient time.

A pump can be defined as a machine or device which is used to increase the potential and kinetic energy of liquid. Generally pumps are used:-

a. To more liquid from lower elevation to higher elevation.

b. $\quad$ To increase the flow rate of the liquid.

c. To move liquid from lower pressure area to higher pressure area.

All pumps however fall into one of two basic categories hydraulic or hydrostatic.

\subsection{HYDRAULIC PRINICIPLES}

Hydraulics work on Pascal's law which state that pressure applied any share to a body of confined liquid is transmitted undiminished to every portion of surface of the containing vessel. Force applied is transmitted in the vessel undiminished. Force applied will tend to push not the lower piston. The force applied in small area is overcome in the piston, having larger area 


\section{Material And Methods \\ EFFICIENCY OF THE HDYRAULIC JACK}

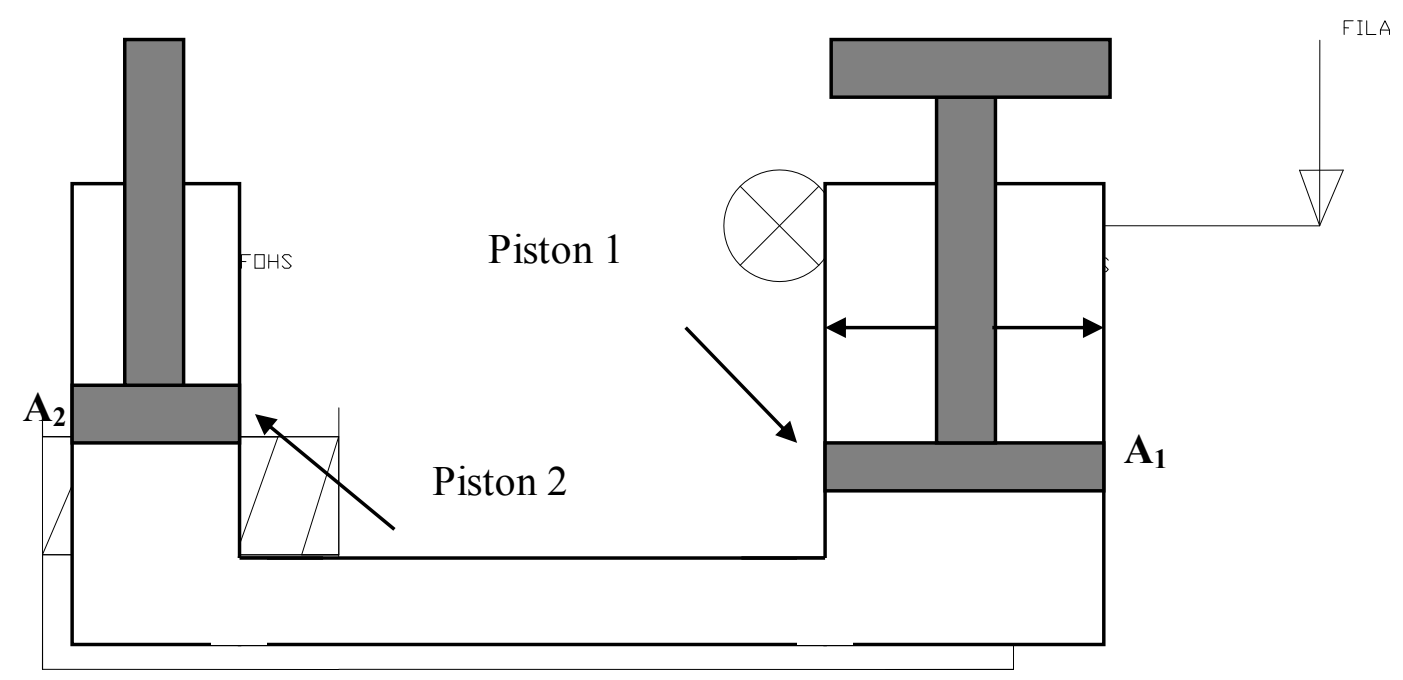

Fig 3.0: Hydraulic Principle

Fig 3.0 Line Diagram of Hydraulic Jack Operation

From the figure above, $\mathrm{FI}_{\mathrm{LA}}$ is the input force applied by the operator on the lever arm, $\mathrm{FO}_{\mathrm{LA}}$ is the output force of the lever arm which is equal to $\mathrm{FI}_{\mathrm{HS}}$, the input force on the hydraulic system. $\mathrm{FO}_{\mathrm{HS}}$ is the output force of the hydraulic system to overcome the load to be lifted.
$\mathrm{MA}_{\mathrm{TOTAL}}=\mathrm{MA}_{\mathrm{LA}} \times \mathrm{MA}_{\mathrm{HS}}$
(XLIV)

Source: (Expositor,20/8/09)

where: MA $_{\text {TотАL }}=$ Over all mechanical advantage

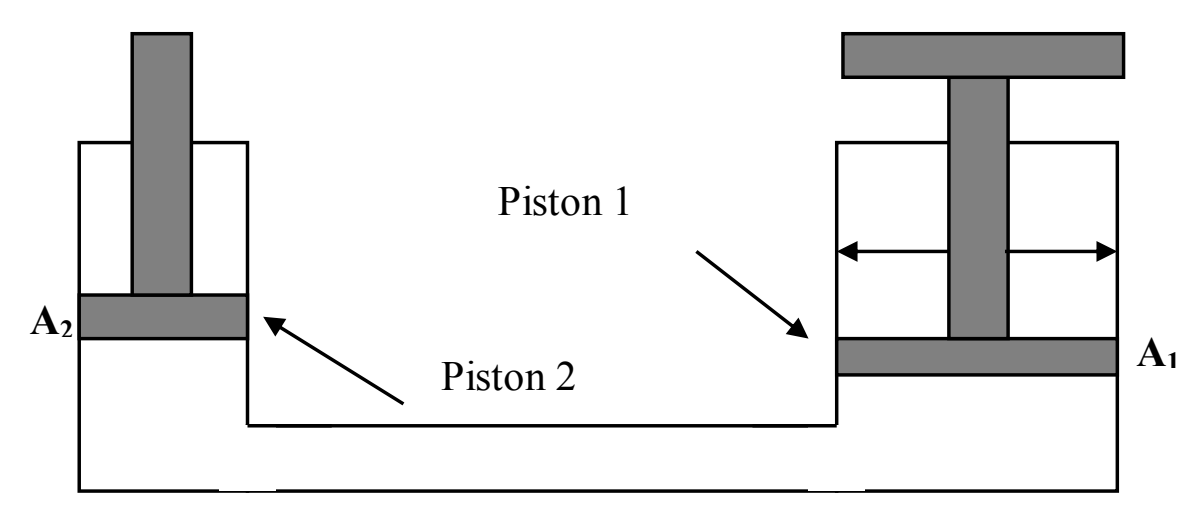

Fig 3, 1: Hydraulic Principle

$\mathrm{MA}_{\mathrm{LA}}=$ Lever arm mechanical advantage

$\mathrm{MA}_{\mathrm{HS}}=$ Hydraulic system mechanical advantage

Recall;

$\mathrm{MA}_{\mathrm{LA}}=10$

$$
\mathrm{MA}_{\mathrm{HS}}=\frac{D^{2}}{d^{2}}
$$

where: $\mathrm{D}=$ Actual diameter of main piston calculated $(\mathrm{mm})$

$\mathrm{d}=$ Actual diameter of minor piston calculated $(\mathrm{mm})$

$\mathrm{MA}_{\mathrm{HS}}=\frac{(34.97)^{2}}{(9.6)^{2}}$

$=13.269$ 
$\mathrm{MA}_{\text {TOTAL }}=10 \times 13.269$

$$
\eta=\left[\frac{F O_{H S}}{F_{L A} X M A_{T O T A L}}\right] \times 132.69
$$

Source: (Expositor, 20/8/2009)

where: $\eta=$ Preferred efficiency of the jack $(\%)$

$F O_{H S}=49050 \mathrm{~N}$ (Given)

$$
\begin{aligned}
& \eta=\left[\frac{49050}{375 \times 132.69}\right] \times 100 \\
& =98.6 \%
\end{aligned}
$$

(Anthony, 1994) recommended the volumetric efficiency of $85-99 \%$ for a hydraulic system that employed hydraulic fluid of optimum viscosity range $\left(13-860 \mathrm{~mm}^{2} / \mathrm{s}\right)$ i.e. $[0.01-0.5 \mu(\mathrm{kg} / \mathrm{ms})]$. The value of volumetric efficiency obtained is however found to be appropriate if the hydraulic fluid selected is adapted and pressure loss is greatly reduced.

result in satisfactory operation of the machine. Certainly, judgment and experience must be exercised in such a process. It is cost effective to test prototypes with a range of tolerances to observe the limits of acceptable performance.

In general, the production of parts with big tolerance on their dimensions requires multiple processing steps like casting or forging, turning, grinding, honing, etc. it should however believe that, a finer surface finish attracts an increase in cost.

Table 3.1 USA Standard B4, 1 - 1967 (1974), Preferred Limits and Fits for Cylindrical Parts, Sponsored by the

\begin{tabular}{|l|l|c|c|c|c|}
\hline \multicolumn{1}{|c|}{ ITEM } & SIZE & GRINDING & HONING & REAMING \\
\hline S/N & \multicolumn{1}{|c|}{ ASMEA } & \pm 0.14 & \pm 0.25 \\
\hline 2 & Piston & $\emptyset 10-15$ & \pm 0.21 & \pm 0.18 & \pm 0.28 \\
\hline 3 & Piston & $\emptyset 36-40$ & \pm 0.23 & \pm 0.14 & \pm 0.25 \\
\hline 4 & Internal Cylinder & $\emptyset 10-15$ & \pm 0.21 & \pm 0.18 & \pm 0.28 \\
\hline
\end{tabular}

From the figure above, the tolerances recommended for the major components of the hydraulic jack based on the machining processes that could be adapted are:-

The minor piston and cylinder of external diameter and internal diameter $10 \mathrm{~mm}$ and $10.5 \mathrm{~mm}$ respectively are given the tolerances of $\pm 0.21 \mathrm{~mm}$ for grinding, $\pm 0.14 \mathrm{~mm}$ for honing and $+0.25 \mathrm{~mm}$ for reaming. However, the main piston and cylinder of external and internal diameter $35 \mathrm{~mm}$ and $35.5 \mathrm{~mm}$ respectively are given the tolerances of $\pm 0.23 \mathrm{~mm}$ for grinding, $\pm 0.18 \mathrm{~mm}$ for honing and $\_0.28 \mathrm{~mm}$ for reaming.

\section{Discussion Of Results:}

Many testing approach was conducted on the parts to be produce in local fabrication of hydraulic jack, some of them include visual observation where the materials suspected were picked and closely inspected to predict thetype material. Spark test was also another method that was used in the material selection, samples are obtained from the parts of the original jack and grinded using grinding machine, the length of the spark producedby the sample of the original jack and aluminum is compared from the result obtained, the base of the jack is suspected to be made of cast iron while the piston and cylinders are made of steel.

Hardness test was conducted on piston, cylinder and jack base using Rockwell hardness tester to measure the depth of penetration for materials of different hardness range.

Tensile strength test was also conducted on the piston, cylinder and jack base. The equipment used for the test is hydraulically operated tensile test machine. The tensile test can be used to ascertain several mechanical properties of materials that are important in design.

The jack was tested in two different ways, tested on load and tested under no load, when tested under no load the first observation seen was leakage within the main cylinder and the base. The second test was conducted still under no load, the piston was jack up but when it was pressed down by the operator's hand, it went down easily. It was observed that the rubber seals at the base were not properly positioned.

When tested on load the jack was used to raise one side of Toyota Hiace bus for about 10 minutes before the pressure was released, it was observed that the side of vehicle was lifted up and leakage was found.

\section{Conclusion And Recommendations}

After trouble shooting, it was observed that when pumping the hydraulic oil into the line, the oil is not retained due to poor operation of the valves. To address this, the valve seating was chamfered to allow the valves to be properly seated on the orifice. The jack was reassembled and retested under load and found working well without leakage. 
It is recommended that the jack should not be used outside the range ofambient temperature as recommended by the manufactures.

\section{References}

[1]. Anthony E. (1994) Fluid Power with Application $3^{\text {rd }}$ Edition, Prentice Hall Englewood Cliffs NJ

[2]. Araromi O.T. (2005), Design and construction of Bean Separating Machine, Bachelor of Science Degree Project Submitted to Department of Mechanical Engineering University of Ibadan (Unpublished)

[3]. Deaconnescu T. and Deaconescu A. (20/8/09), An analysis of the sealing element - hydraulic cylinder tribosystem, www.ith.selhyddemo/frames.html.

[4]. Epositor A. (20/8/09) Mechanical Advantage and Efficiency of Hydraulic jack, www.technologyinterface.nmsu.edu/3 $2 / 3 \quad 3 \mathrm{fhtml}$.

[5]. Hadanbosi C. and Fairman J.G., (13/10/09) Pascal's Principle and Hydraulic, www.gre.nasa.gov.

[6]. Hall, Hollowenko A.R. and Laughlin H.G. (1980) Schaum's outline series; theory and problems of machine design metric edition.

[7]. Ingree (1986) Metal work theory book, spectrum book publishing company, Ibadan.

[8]. John V.B. (1992) Introduction to Engineering materials, $3{ }^{\text {rd }}$ Edition, ELBS Imprint Hongkon

[9]. Kalpakjian S. and Schmid S.R. (2004), Manufacturing Engineering and technology, Pearson Education Limited, Singapore.

[10]. Khurmi S.R. (2006), Strength of materials (mechanics of solids) $23^{\text {rd }}$ Edition, S. Chand and company limited, New Delhi. Leamstar. M.H.A. (1975), Material for Engineering, $3^{\text {rd }}$ Edition, Holder and Stoughton, London.

[11]. Mc Din B. (1967) Modern Survey Hydraulic Machinery and Pneumatic power, Cret Publishers, London.

[12]. Mott R.L. (1985) Machine Elements in mechanical design, Charles E. Merril publishing company, Ohio, USA.

[13]. Rayput K. (2004) Fluid Mechanism and Hydraulic Machine S. Chand and company limited, New Delhi.

[14]. Short Bolt C.R. (1977), Technician Workshop Process and Material book, Cassell Publishing Company London.

[15]. Stephens R.C. (1978) strength of Materials, Reprint Edition Edward Arnold Publishign Limited, London.

[16]. Umar A.A. and Abdullahi I. (2006), manufacture of IHRC 230F Transmission coupling using reverse Engineering; Nigeria Journal of Engineering Research and Development Vol. 5.

[17]. Whitney R.J. (1958) The strength of the lifting action in Man; journal on Ergonomics, vol. 1 